\title{
A FORMULA FOR PREDICTION OF CEILING JET TEMPERATURE IN TWO LAYER ENVIRONMENT
}

\author{
WATANABE Jun-ichi, SHIMOMURA Shigeki and AOYAMA Youichi \\ Analytical Evaluation \& Reliability Technology Center, Corporate Quality \\ Assurance Department, Matsushita Electric Works Ltd. \\ 1048 Kadoma, Osaka 571-8686, JAPAN
}

TANAKA Takeyoshi

Disaster Prevention Research Institute, Kyoto University

Gokasho, Uji, Kyoto 611-0011, JAPAN

\begin{abstract}
The means for predicting ceiling jet temperature under an unconfined ceiling has been well established by the previous work under an unconfined ceiling. However, a room ceiling is usually enclosed by walls so a fire plume rises in a stratified environment in the event of room fire. Previous work under an unconfined ceiling will not be sufficient to predict the ceiling jet temperature in such a configuration. On the other hand, a two layer zone model is often used for predicting fire temperature in a stratified configuration but it only gives average condition in the upper layer, which is too crude to predict the near ceiling temperature to assess the actuation of ceiling mounted detectors and sprinklers.
\end{abstract}

In this study, a formula for ceiling jet temperature in a two layer configuration was derived by combining previous work under an unconfined ceiling, upper layer temperature and layer interface height. The validity of the formula was examined by comparing the results of prediction and the experiments using the test fires prescribed in an ISO/TC21/SC3 draft standard. The predicted ceiling temperatures generally exhibit satisfactory agreement with the measured temperatures.

KEY WORDS : ceiling jet, ceiling layer, fire detection, enclosure fire

\section{INTRODUCTION}

Progress in the area of fire safety engineering in recent decades has induced an irreversible trend towards performance-based design methods of buildings. However, progress towards performance-based assessment of fire detection system until now seems to be slow. The assessment of fire detectors still primarily depends upon prescribed test methods such as EN54-9 [1], a test method for sensitivity to fire of automatic fire detection system and an ISO/TC21/SC3 draft standard [2], a international test method for smoke detector developed based on EN54-9.

However, the response of a detector in an actual fire will differ from one case to another depending on the conditions of the fire source and the room in which the detector is equipped. In order to assess detector response performance in a variety of conditions, it is vital to have a means which one enables to predict the response as a function of fire source and room geometry.

FIRE SAFETY SCIENCE--PROCEEDINGS OF THE SEVENTH INTERNATIONAL SYMPOSIUM, pp. 431-442 
Although consideration needs to be made in many aspects to achieve this goal one of the most important issues is to develop a model to predict the ceiling jet temperature in realistic fire environment. A ceiling in a room is a confined ceiling, bounded by walls so a hot gas layer is expected to develop under the ceiling in the event of fire. The fire plume rising in such a stratified environment entrains hot gases from the upper layer as well as ambient air from the lower layer, which will affect the plume temperature, hence the ceiling jet.

In case of unconfined horizontal ceiling, the well-established equations derived by Alpert [3] is available to predict the ceiling jet temperature and velocity. A formula by Heskestad [4] can be used for the same purpose. In case of unconfined slant ceilings, the prediction methods were also proposed by Sugawa [5] for example.

For the prediction of upper layer temperature, on the other hand, a two layer zone model is usually employed [6][7]. But such a model can only gives layer average temperature, which is too crude to predict near ceiling temperatures for the purpose of assessing detector response.

The prediction of ceiling jet temperature in two layer environment was tried by Evans, who proposed a method of prediction in terms of a set of non-dimensional formulas [8]. Cooper also proposed a method to predict ceiling jet temperature in the same configuration [9]. Yamauchi extended the Evans' method to develop the prediction method for response time of smoke detectors [10]. Hasemi and Sako et al applied the Evans' method to generate the correlation of the ceiling jet temperatures measured in their experiments [11]. These methods seem to exhibit a certain extent of success but most of the calculation procedures basically address steady state conditions and may be somewhat complex for many practitioners.

In this study, a very simple formula for predicting the ceiling jet temperature in two layer environment was derived taking into account the plume entrainment in two layer configuration and combining the Reference [3] equations, upper layer temperature and layer interface height. The predictions by the formula were compared with the transient ceiling jet temperatures measured in the experiments using three of the fire sources prescribed in Reference [1][2]. The agreement was satisfactory in the three experiment cases.

\section{THE MODEL}

\subsection{Ceiling Jet Temperature in Stratified Environment}

As illustrated by Fig. 1, a plume rising from the floor of a room is considered. The air in the room is assumed to be stratified into a hot upper layer at temperature $T_{s}$ and a cold layer at temperature $T_{a}$, each of which is uniform in temperature.

Letting $m_{p}\left(Z_{a}\right)$ be the plume mass flow rate at the height of layer interface $Z_{a}$ and $m_{p}(H)$ be the mass flow rate at the height of ceiling $H$, the energy conservation for the plume is described as 


$$
c_{p} T_{a} m_{p}\left(Z_{a}\right)+c_{p} T_{s}\left\{m_{p}(H)-m_{p}\left(Z_{a}\right)\right\}+Q_{c}=c_{p} \overline{T(H)} m_{p}(H)
$$

where $Q_{c}$ is the convective component of the heat release rate and $\overline{T(H)}$ is the plume average temperature at the ceiling height H. From Eq.(1), the average temperature rise at the height of $H$ can be obtained as follows:

$$
\overline{\Delta T(H)} \equiv \overline{T(H)}-T_{a}=\left\{1-\frac{m_{p}\left(Z_{a}\right)}{m_{p}(H)}\right\}\left(T_{s}-T_{a}\right)+\frac{Q_{c}}{c_{p} m_{p}(H)}
$$

The second term in the right hand side of Eq.(2) denotes the plume average temperature rise when the plume environment is ambient, or more generally uniform, at the ceiling height, that is,

$$
\frac{Q_{c}}{c_{p} m_{p}(H)}=\overline{\Delta T_{a}(H)}
$$

The first term in the right hand side of Eq.(2) denotes the effect of the upper layer, with temperature $T_{s}$ and interface height $Z_{a}$, on the plume temperature rise.

It is assumed here that the plume mass flow rate in the stratified environment is the same as that in uniform environment regardless the condition of stratification and given by Zukoski [12].

$$
m_{p}(Z)=0.07 Q^{1 / 3} Z^{5 / 3}
$$

where $Q$ is the heat release rate of the fire source. This assumption will be adequate at least in approximate sense for the early stage of fire where the upper layer temperature is not so high if it may not be completely true.

Using Eq.(4) and (3) in Eq.(2) yields

$$
\overline{\Delta T(H)}=\left\{1-\left(\frac{Z_{a}}{H}\right)^{5 / 3}\right\}\left(T_{s}-T_{a}\right)+\overline{\Delta T_{a}(H)}
$$

Eq.(2') gives the relationship of the average temperature rise of plume between uniform and stratified plume environment but not the detailed temperature distribution of the plume impinging upon a ceiling. Nevertheless, it is naturally presumed that Eq.(2') may be converted to a relationship to give the ceiling jet temperature in stratified configuration if the second term of the right hand side is replaced with the Reference [3] equations. In other words,

$$
\Delta T_{c}(H, r)=\left\{1-\left(\frac{Z_{a}}{H}\right)^{5 / 3}\right\}\left(T_{s}-T_{a}\right)+\Delta T_{A l p}(H, r)
$$

where $\Delta T_{c}(H, r)$ is the ceiling jet temperature in the stratified configuration as a function of ceiling height $H$ and the distance from the plume axis $r$, and $\Delta T_{A l p}(H, r)$ is the Reference [3] equations for unconfined ceiling jet temperature, which has been given as

$$
\Delta T_{A l p}(H, r)= \begin{cases}16.9\left(\frac{Q^{2 / 3}}{H^{5 / 3}}\right) & \left(\frac{r}{H} \leq 0.18\right) \\ \left.5.38\left(\frac{Q^{2 / 3}}{H^{5 / 3}}\right) \frac{r}{H}\right)^{-2 / 3} & \left(\frac{r}{H}>0.18\right)\end{cases}
$$

where $\mathrm{Q}$ is the heat release rate of the fire source[3]. 
Eq.(5) suggests that the ceiling jet temperature at an arbitrarily stratified configuration, i.e arbitrary upper layer temperature and layer interface height can be predicted. When there is no upper layer, in which case $Z_{a}=H$ and also $T_{s}=T_{a}$, Eq.(5) is reduced to the Reference [3] equations, and when a room is entirely filled with an upper layer Eq.(5) gives the ceiling jet temperature in the ambient whose temperature is elevated to $T_{s}$.

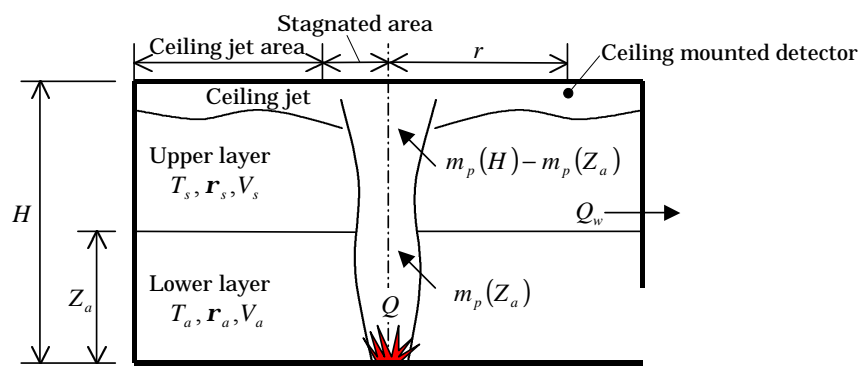

FIGURE 1. Schematic of ceiling jet in two layer environment

\subsection{Two Layer Zone Model}

Eq.(5) needs to be further supplemented with the predictions of the upper layer temperature $T_{s}$ and the layer interface height $Z_{a}$ to predict the ceiling jet temperature. Obviously, a two layer zone model is appropriate for this purpose. Although a number of two layer zone models are already available, a simple two layer zone model was newly constructed in this study for such existing models are generally so sophisticated that they are not necessarily convenient to apply to such a simple issue as this particular case.

Since the primary interest in this study lies in the relatively early stage of fire, such as smoke filling period, the two layer zone model only addresses the upper layer properties.

(1) Relationship for upper layer

For the upper layer, the following relationships hold:

(a) Mass conservation

Considering no vent flow associated with upper layer, the fire plume is the only mechanism to add mass to the upper layer, hence

$$
\frac{d}{d t}\left(\rho_{s} V_{s}\right)=m_{p}\left(Z_{a}\right)
$$

where $\rho_{s}$ and $V_{s}$ are the density and the volume of the upper layer, respectively. $m_{p}\left(Z_{a}\right)$ is the plume mass flow rate at the height of the layer interface.

(b) Energy conservation

Although it is said that $30 \%$ or so of the heat released by combustion of fire source is lost by flame radiation, it is assumed here that all the heat released is conveyed to the upper layer by the fire plume for the first order approximation since it is considered that a significant portion of the radiated heat is absorbed by the upper layer itself and a part of the rest absorbed by the lower part of the wall is re-radiated to the upper layer. Based on this assumption, the energy conservation of the upper layer can be written as

$$
\frac{d}{d t}\left\{c_{p} T_{s}\left(\rho_{s} V_{s}\right)\right\}=Q-Q_{w}+c_{p} T_{a} m_{p}\left(Z_{a}\right)
$$


where $Q$ is the heat release rate of the fire source and $Q_{w}$ is the heat loss from the layer to the room boundary.

(c) Gas state

The effect of the pressure change induced by fire on air density is normally negligible, so the equation of ideal gas state is reduced to the following equation:

$$
\rho_{s} T_{s}=\rho_{a} T_{a}
$$

(2) Upper layer temperature and layer interface height

From Eqs.(7), (8) and (9), the coupling ordinary equations for the upper layer temperature and the layer interface height can be derived as follows:

(a) Upper layer temperature

Noting that the left hand side of Eq.(8) can be developed as

$$
\frac{d}{d t}\left\{c_{p} T_{s}\left(\rho_{s} V_{s}\right)\right\}=c_{p} \rho_{s} V_{s} \frac{d T_{s}}{d t}+c_{p} T_{s} \frac{d}{d t}\left(\rho_{s} V_{s}\right)
$$

and calculating Eq.(8)- $c_{p} T_{s}$ xEq.(7) yields the ordinary differential equation for the upper layer temperature as follows:

$$
\frac{d T_{s}}{d t}=\frac{Q-Q_{w}-c_{p}\left(T_{s}-T_{a}\right) m_{p}\left(Z_{a}\right)}{c_{p} \rho_{s} V_{s}}
$$

(b) Layer interface height

Eq.(7) can be developed as

$$
\rho_{s} \frac{d V_{s}}{d t}+V_{s} \frac{d \rho_{s}}{d t}=m_{p}\left(Z_{a}\right)
$$

On the other hand, from Eq.(9)

$$
\frac{d \rho_{s}}{d t}=-\frac{\rho_{s}}{T_{s}}\left(\frac{d T_{s}}{d t}\right)
$$

Using Eqs.(10) and (12) into (11) yields the differential equation for the upper layer volume as follows:

$$
\frac{d V_{s}}{d t}=\frac{Q-Q_{w}+c_{p} T_{a} m_{p}\left(Z_{a}\right)}{c_{p} \rho_{s} T_{s}}
$$

In a particular case that the room horizontal section area $A_{R}$ is constant with height, $V_{s}=A_{R}\left(H-Z_{a}\right)$, in other words $d V_{s} / d t=-A_{R}\left(d Z_{a} / d t\right)$, Eq.(13) becomes the equation for the layer interface height as follows:

$$
\frac{d Z_{a}}{d t}=-\frac{Q-Q_{w}+c_{p} T_{a} m_{p}\left(Z_{a}\right)}{c_{p} \rho_{s} T_{s} A_{R}}
$$

(2) Component Processes

Although Eqs.(10) and (14) can be said to be the most basic equations in this zone model, sub-models for fire plume and heat transport need to be further incorporated to complete the equations.

(1) Fire plume flow rate

Eq.(4) is used for the mass flow rate of the fire plume, i.e. $m_{p}\left(Z_{a}\right)$ in Eqs.(10) and (14).

(2) Heat transfer to room walls 
The heat transfer from the upper layer to walls consists of the thermal radiation and the convective heat transfer. In this model, the rate of heat transfer from the upper layer to the room boundary is divided into three parts: the heat transfer to the ceiling(w1), to the part of the walls contacting with upper layer(w2) and the floor and the part of wall contacting with lower layer(w3). Schematic of the heat loss rate from the upper layer is shown in Fig.2. The heat flux from the smoke layer to each of the parts are given as

$$
\begin{aligned}
& q_{w 1}^{\prime \prime}=\varepsilon_{w} \varepsilon_{s} \sigma\left(T_{s}^{4}-T_{w 1}^{4}\right)+h\left(T_{s}-T_{w 1}\right) \\
& q_{w 2}^{\prime \prime}=\varepsilon_{w} \varepsilon_{s} \sigma\left(T_{s}^{4}-T_{w 2}^{4}\right)+h\left(T_{s}-T_{w 2}\right) \\
& q_{w 3}^{\prime \prime}=\varepsilon_{w} \varepsilon_{s} \sigma\left(T_{s}^{4}-T_{a}^{4}\right)
\end{aligned}
$$

where $h$ is the convective heat transfer coefficient, of which value $h=0.015 \mathrm{~kW} / \mathrm{m}^{2}$ was assumed in this model. $\varepsilon_{w}$ is the emissivity of the room boundary surface, which is approximated to be $\varepsilon_{w}=1$ at any part. $\varepsilon_{s}$ is the emissivity of the upper layer, of which assumed to be $\varepsilon_{s}=1$ since the present model does not predict the concentrations of gaseous nor solid component in the upper layer. $T_{\mathrm{w} 1}$ and $T_{\mathrm{w} 2}$ are the surface temperatures of the ceiling and the part of the wall contacting with the upper layer, respectively. The surface temperature of the floor and the lower part is assumed to remain constant at $T_{a}$.

Using Eq.(15), the total heat loss rate from the upper layer is calculated as

$$
Q_{w}=q_{w 1}^{\prime \prime} A_{R}+q_{w 2}^{\prime \prime} L\left(H-Z_{a}\right)+q_{w 3}^{\prime \prime} A_{R}
$$

where $L$ is the perimeter of the room.

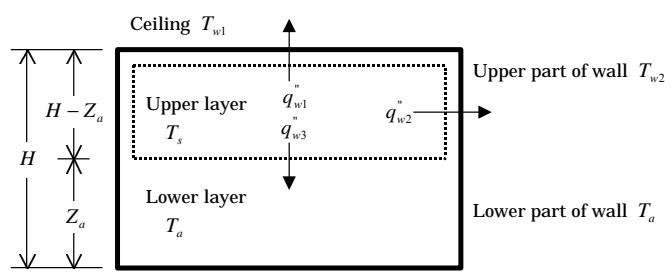

FIGURE 2. Schematic of the heat loss rate from the upper layer

(3) Wall surface temperature

The surface temperatures $T_{\mathrm{w} 1}$ and $T_{\mathrm{w} 2}$ in Eq.(15) are calculated by numerically solving the following one dimensional heat conduction equation by finite difference method.

(a) Heat conduction equation

$$
\frac{\partial T}{\partial t}=\left(\frac{k}{c \rho}\right) \frac{\partial^{2} T}{\partial x^{2}}
$$

(b) Boundary condition

$$
-\left.k \frac{\partial T}{\partial x}\right|_{x=0}=q_{i n}^{\prime \prime} \quad \text { and }-\left.k \frac{\partial T}{\partial x}\right|_{x=l}=0
$$

where $k, c$ and $\rho$ are conductivity, specific heat and density of wall material, respectively, and $x$ is the distance from the interior surface and 1 is the thickness of the wall. $q$ in is the heat flux to the interior surface, which is given as follows 


$$
q_{i n}^{\prime \prime}=\left\{\begin{array}{lc}
q_{w 1}^{\prime \prime} & (\text { ceiling }: \mathrm{w} 1) \\
q_{w 2}^{\prime \prime} & (\text { side wall }: \mathrm{w} 2)
\end{array}\right.
$$

depending on the part being considered.

\section{COMPARISON BETWEEN THE PREDICTION AND THE EXPERIMENTS}

The ceiling jet temperature predicted using the above two layer zone model and Eq.(5) were compared with the temperature measured in the room fire experiments using the test fires prescribed in the ISO/TC21/SC3 draft standard [2] as the fire source.

\subsection{The Experiment}

\section{(1) Fire room}

The room used for this series of fire experiments is the room constructed for the detector performance tests and complies with the conditions prescribed in the ISO/TC21/SC3 draft standard [2]. The width, the depth and the ceiling height of the room are $10 \mathrm{~m}, 7 \mathrm{~m}$ and $4 \mathrm{~m}$, respectively. The ceiling is made of calcium silicate and the wall is made of normal concrete, with exception of two doors and observation windows. The fire source in the experiment was located on the floor at the center of the room.

\section{(2) Fire sources}

Reference [2] prescribes several types of fire sources (TF: = Test Fire) for detector response tests. In this series of experiments, three types of TFs shown in TABLE 1 were employed since the heat release rates of these TFs are relatively large compared with the others, thereby the temperature measurements are easier.

\section{(3) Measurements}

(a) Temperature

The array of thermocouples in the experiments is shown in Fig. 3. The thermocouples to measure the ceiling jet temperature were arrayed $0.05 \mathrm{~m}$ below the ceiling, one in the center and the other $3 \mathrm{~m}$ from the center. Although the position of the maximum ceiling jet temperature under the ceiling is not clear it is assumed that the temperature at $5 \mathrm{~cm}$ below the ceiling is not very far from the maximum temperature. Thermocouples were also arrayed vertically at $2.5 \mathrm{~m}$ and $4.0 \mathrm{~m}$ from the room center with $0.75 \mathrm{~m}$ spacing to measure the vertical temperature distribution in the layer.

(b) Heat release rate

The transient heat release rate of each of the fire sources was calculated from the mass burning rate, measured using an electronic balance, and the heat of combustion indicated in TABLE 1. The heat release rates of the three TFs thus obtained are shown in Fig. 4.

\subsection{Comparison and Discussion}

\section{(1) Calculation conditions}

The same conditions as the experiments were used as those of the calculations for predicting the ceiling jet temperatures. The heat release rate of each fire source was the same as that shown in Fig. 4. The data shown in TABLE 2 were used as the thermal properties of the ceiling and the wall. 


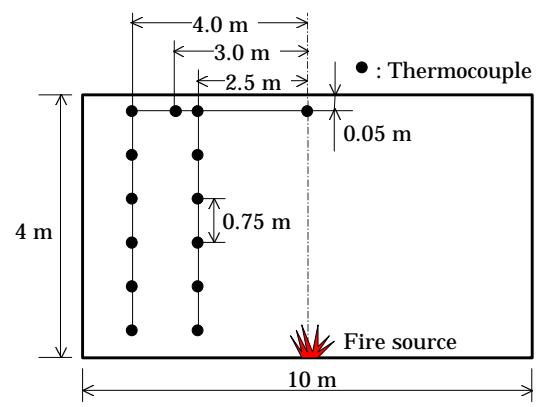

FIGURE 3. Array of thermocouples

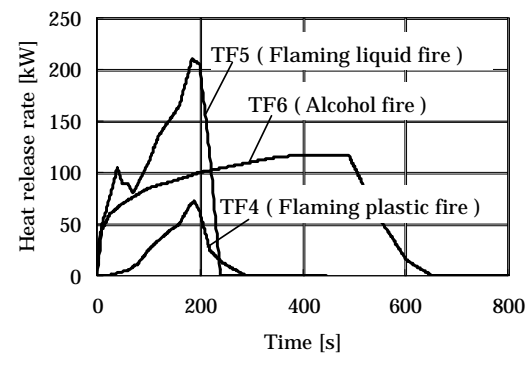

FIGURE 4. Heat release rates of the fire sources

TABLE 1. Calorific value of fuels of TFs

\begin{tabular}{|c|c|c|}
\hline Fire type & Fuels & Calorific value $[\mathrm{kJ} / \mathrm{g}]$ \\
\hline TF4 & Polyurethane & 22 \\
\hline TF5 & n-heptane & 45 \\
\hline TF6 & alcohol & 26 \\
\hline
\end{tabular}

TABLE 2. Properties of ceiling and wall material

\begin{tabular}{|c|c|c|c|c|c|}
\hline Part & Material & $\begin{array}{c}\text { Density } \\
{\left[\mathrm{kg} / \mathrm{m}^{3}\right]}\end{array}$ & $\begin{array}{c}\text { Specific heat } \\
{[\mathrm{kJ} / \mathrm{kgK}]}\end{array}$ & $\begin{array}{c}\text { Thermal } \\
\text { Conductivity } \\
{[\mathrm{kW} / \mathrm{mK}]}\end{array}$ & $\begin{array}{c}\text { Thickness } \\
{[\mathrm{m}]}\end{array}$ \\
\hline Wall & Concrete & 2400 & 0.90 & $1.2 \times 10^{-3}$ & 0.1 \\
\hline Ceiling & $\begin{array}{c}\text { Calcium } \\
\text { silicate }\end{array}$ & 622 & 0.92 & $0.13 \times 10^{-3}$ & 0.1 \\
\hline
\end{tabular}

(2) The upper layer temperatures measured and predicted by the two layer zone model An example of the comparison between the upper layer temperatures from the measurement in the experiments and from the prediction using the two layer zone model is shown in Fig. 5. This specific example is the case for TF6(alcohol fire). The thin dashed line indicates the ceiling temperature at the room center, the thin solid lines indicate the temperature recorded by the thermocouples at each height arrayed at $2.5 \mathrm{~m}$ from the room center, the thick solid line indicates the upper layer average temperature reduced from the measurements by the $\mathrm{N} \%$ method introduced by Cooper et al (see Note) and the thick gray line indicates the upper layer temperature predicted by the two layer zone model.

As can be seen in Fig. 5, the predicted upper layer temperature and the upper layer average temperature from the measurements generally show good agreement. However, the ceiling jet temperatures are considerably higher than the upper layer average.

(3) The ceiling jet temperature measured and predicted by the Reference [3] equations An example of the comparison between the ceiling jet temperature measured in the experiments and predicted by the Reference [3] equations is shown in Fig. 6. The example is also the case for TF6(alcohol fire). 
As can be seen in Fig. 6, the measured ceiling temperatures are very far from the prediction by the Reference [3] equations. It is, therefore inappropriate to apply the Reference [3] equations to stratified configuration, which might be easily expected.
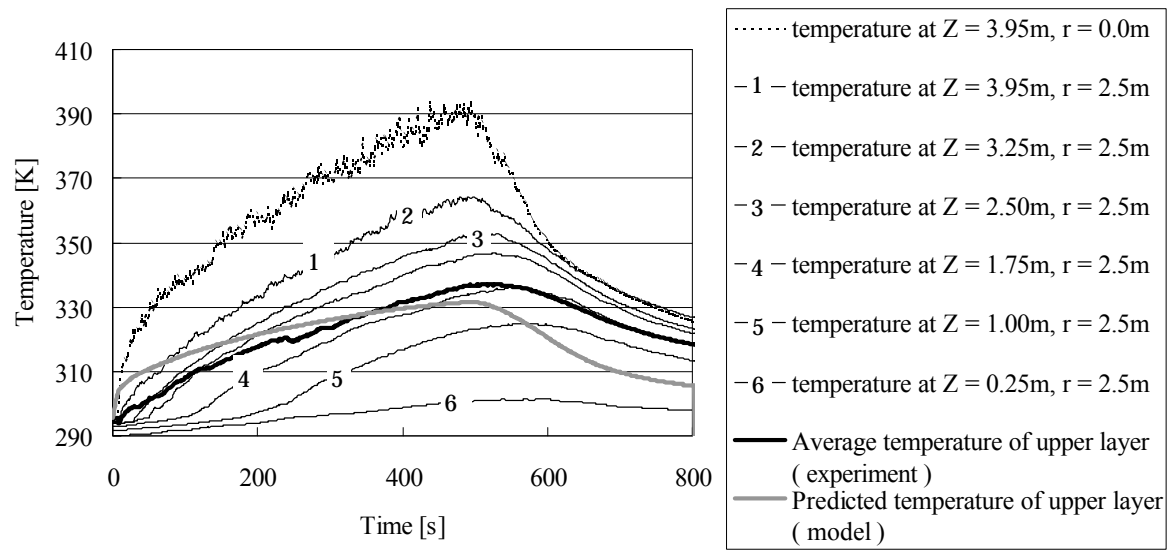

FIGURE 5. Comparison of temperatures between experiment and prediction by the two layer zone model ( An example for TF6 )

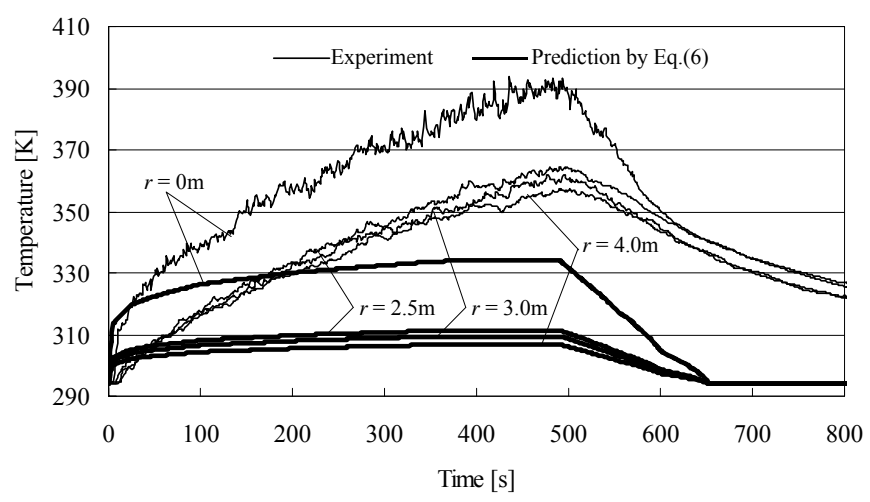

FIGURE 6. Comparison of ceiling jet temperatures between experiment and prediction by the Reference [3] equations ( An example for TF6 )

(4) The ceiling jet temperature measured and predicted by the present model

The results of comparisons between the ceiling jet temperatures measured in each of the experiments and predicted by Eq.(5) proposed in this study are shown in Figs. 7, 8 and 9, correspondingly to the TF4, 5 and 6.

From these figures, it is shown that the prediction of the ceiling jet temperature is remarkably improved from the predictions shown in Figs. 5 and 6 as long as the growing stage of the fires is concerned, although slight difference which is suspected to be caused by some error involved in the measurements or the zone model is observed. Incidentally, although the results in Fig. 7 through 9 are purely from prediction, the same level of agreement is expected if the measured layer average temperatures are used instead of the 
predicted upper layer temperature for both agree well as shown in Fig. 5.

So it may be said the present model, described by Eq.(5) is satisfactory for the purpose of fire detection. However, from the view point of a fire model, the model needs to be further improved since the predicted temperatures gradually part from the measurement and go down to the layer average temperature at the decaying stage of the fire source.

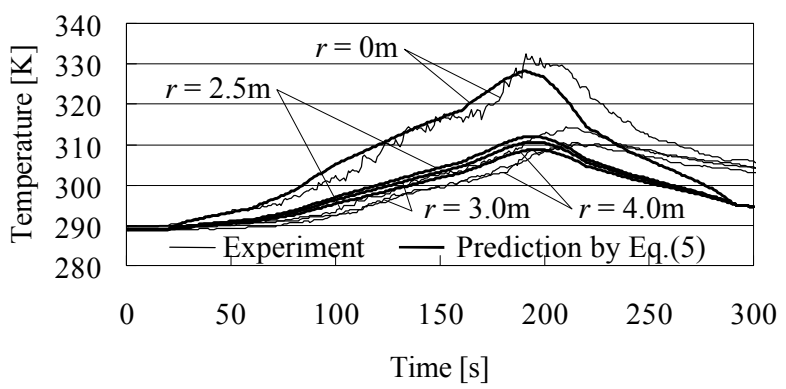

FIGURE 7. Comparison of ceiling jet temperatures between experiment and prediction by Eq.(5) for TF4

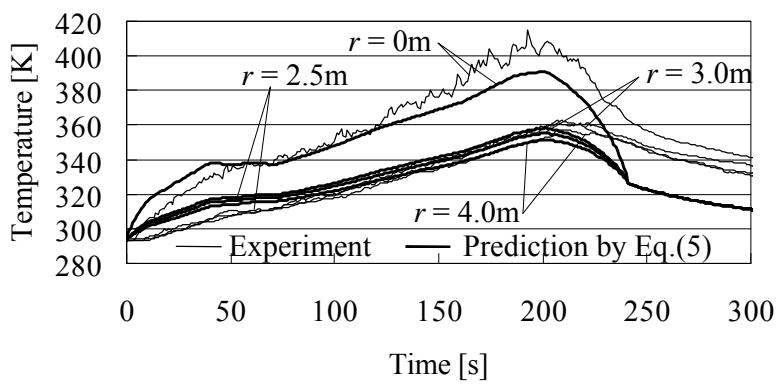

FIGURE 8. Comparison of ceiling jet temperatures between experiment and prediction by Eq.(5) for TF5

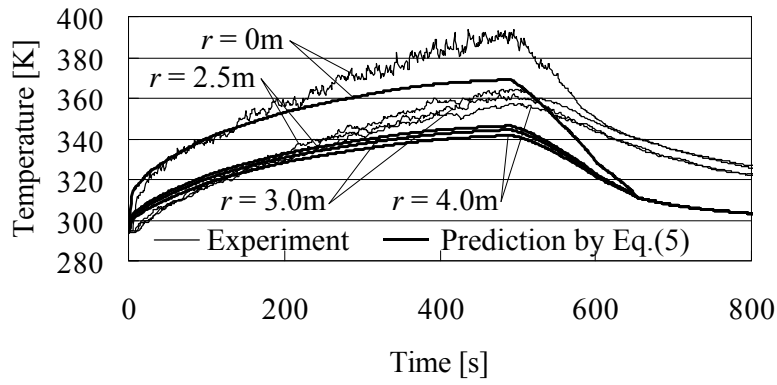

FIGURE 9. Comparison of ceiling jet temperatures between experiment and prediction by Eq.(5) for TF6 


\section{CONCLUSION}

A formula for predicting ceiling jet temperature in confined ceiling configuration described by Eq.(5), which was derived by combining the Reference [3] equations, upper layer temperature and layer interface height, exhibits satisfactory agreement with the transient temperatures measured in the experiments conducted in this study. Despite its simple appearance. Eq.(5) is considered to be an effective means to predict ceiling jet temperature in many of the realistic room fire situations.

Note: The upper layer average temperature was reduced by processing the measured temperatures according to the $\mathrm{N} \%$ method introduced by Cooper et al [13], that is

(1) Determine the layer inter face height using $\mathrm{N} \%$ method. $\mathrm{N}=20$ in this study.

(2) Average the temperature recordings of the thermocouples within the defined upper layer.

\section{NOMENCLATURE}

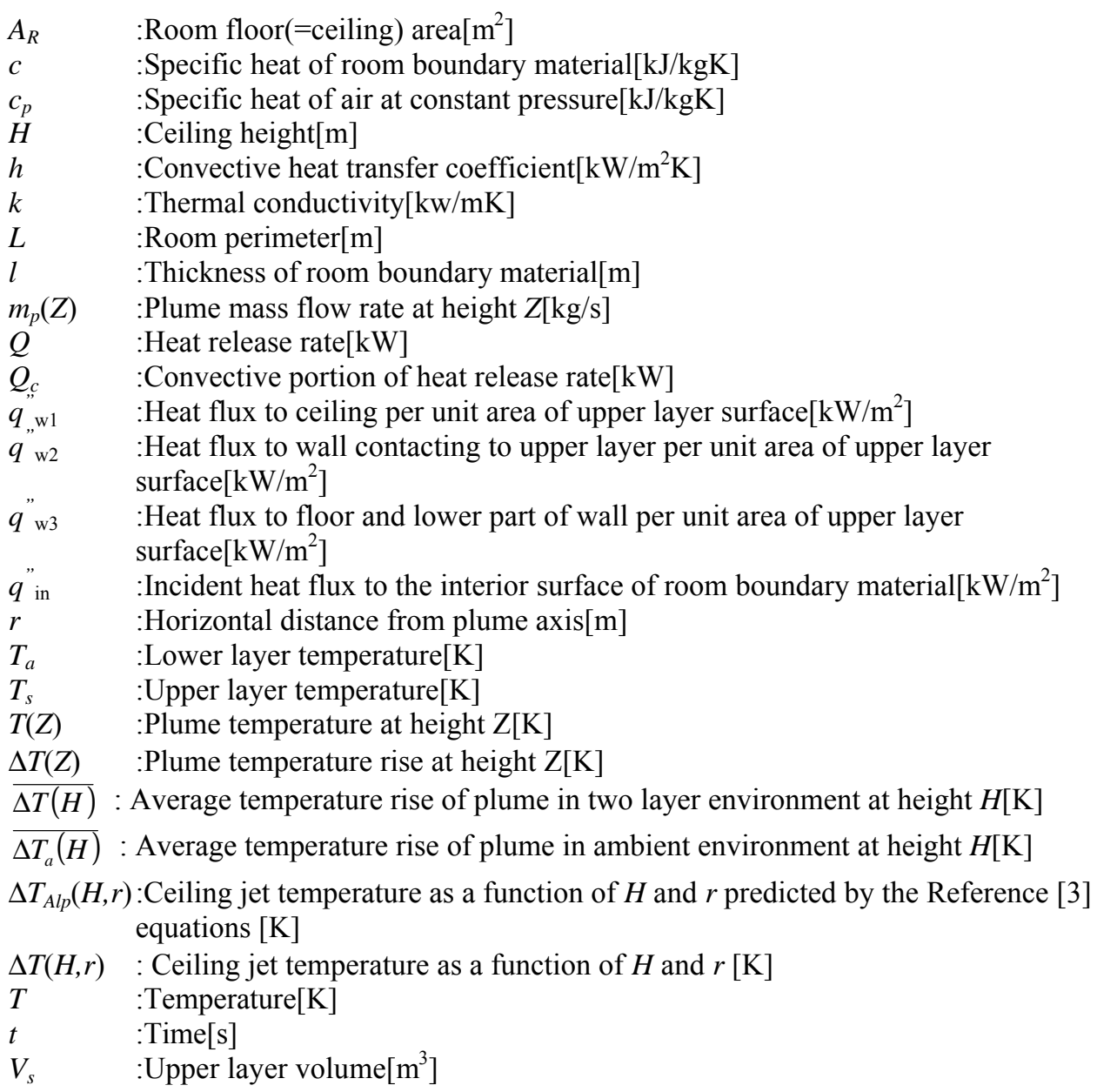


:Depth from the interior surface of room boundary material[m]

$Z \quad:$ :Height from floor[m]

$\varepsilon_{s} \quad:$ Upper layer emissivity[-]

$\varepsilon_{w} \quad:$ Room boundary surface emissivity[-]

$\rho \quad$ :Density of room boundary material $\left[\mathrm{kg} / \mathrm{m}^{3}\right]$

$\rho_{a} \quad$ :Ambient air density $\left[\mathrm{kg} / \mathrm{m}^{3}\right]$

$\rho_{s} \quad:$ Upper layer density $\left[\mathrm{kg} / \mathrm{m}^{3}\right]$

$\sigma \quad$ :Stefan-Boltsmann constant $\left(=5.67 \times 10^{-11} \mathrm{~kW} / \mathrm{m}^{2} \mathrm{~K}^{4}\right)$

\section{REFERENCES}

[1] EN54 Part9, Components of automatic fire detection systems, Part9 : Methods of test of sensitivity to fire, 1984

[2] ISO TC21/SC3, document N301 ( Draft prEN54-7 ), Fire Detection and Fire Alarm Systems, Part7 : Smoke detectors - point detectors using scattered light, transmitted light or ionization , International Organization for Standardization, Geneva, Switzerland, 1997

[3] Alpert, R. L. , Calculation of Response Time of Ceiling-Mounted Fire Detectors, Fire Technology, Vol. 8, No. 3, 1972

[4] Heskestad, G., Physical Modeling of Fire, J. Fire and Flammability, Vol.6 pp. 253-257, 1975

[5] Sugawa, O., Nakamura, N., Ito, A. and Matsubara, Y.," Correlation between Excess Temperature and Flow Velocity under Sloped and Horizontal Ceiling Flow," Summary of papers annual meeting of Japan Association for Fire Science and Engineering, PP.32-35, 2000

[6] Tanaka T. and Nakamura K.," A Model for Predicting Smoke Transport in Building Based on Two Layers Zone Concept -," Report of the Building Research Institute, No.123, Building Research Institute, Ministry of Construction, 1989

[7] Tanaka T., A Model of Multiroom Fire Spread, Fire Science and Technology, Vol.3 No.2, 1983

[8] D.D. Evans, "Calculating Sprinkler Actuation Time in Compartments," Fire Safety J., Vol.9, No. 2, 1985

[9] Cooper L.Y., A Buoyant Source in the Lower of Two, Homogeneous, Stratified Layers, $20^{\text {th }}$ International Symposium on Combustion, Combustion Institute, Pittsburgh 1984

[10] Yamauchi Y.," Prediction of Response Time of Smoke Detectors in Enclosure Fires, "National Bureau of Standards, NBSIR 88-3707, January 1988

[11] Hasemi Y., Sako S.," Thermal Responsiveness of Fusible Sprinkler and Its Actuation below a Confined Ceiling," Bulletin of Japan Association for Fire Science and Engineering, Vol. 38 , No.1 , 1988

[12] Zukoski, E.E., Kubota, T. and Cetegen, B., "Entrainment in Fire Plumes," Fire Safety J., Vol.3, Nos.2-4, 1981

[13] Cooper, L.Y., Harkleroad, M.F., Quintiere, J.G. and Rinkinen, W.J., "An Experimental Study of Upper Hot Layer Stratification in Full-Scale Multiroom Fire Scenarios, “J. of Heat Transfer, Vol.104, pp. 741-749, 1982 